\title{
ENSL82 and CDRL82: The 1982 Version of Evaluated Nuclear Structure Libraries ENSL and CDRL
}

\author{
R. J. Howerton
}

Manuscript Date: January 26, 1983

\author{
DISCLAIMER
}

This report was prepared as an account of work sponsored by an agency of the United States This report was preparad as an accoumt of work sponsored by an agency thereof, nor any of their Government. Neither the United States Government or assumes any legal liability or responsiemployees, make any warateses, or usefulness of any information. apparatus, product, or bility for the accuracy, completeness, or usefulness of any information. process disclowed, or represents that its use would not infringe privalely owned rights

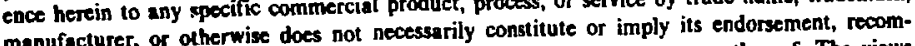
manufacturer, or otherwise does not necessarily constitute or imply its endorsement recome mendation, or favoring by the United States Government or any agency thereof. The views

and opinions of authors expressed herein do nat

\section{LAWRENCE LIVERMORE LABORATORY University of California $\bullet$ Livermore, California $\bullet 94550$}




\section{Foreword}

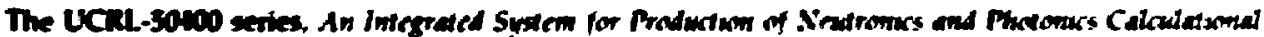

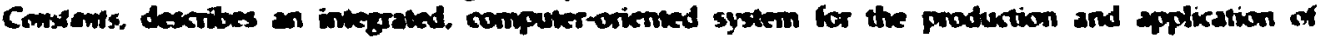
nevtronics and photonics calculational constants.

The system supplies reliable, up-to-date data, selects specific types of data on request, provides output in a variety of forms (ultimately in the form of input to other computer codes), and functions rapidily and efficientiy.

The UCRL-50HO seties comprises the following volumes:

- Vol. 1, Part A, Rev. 3, ECSIL A System for Storage, Retnetal, and Display of Exprenmental Tieutron Dasa. September 1976.

- Vol. 1. Part B. Program ECSX4 (Version 78-1): Comersoon of Expen enfallu Measured Crixs-Suctzen Dafa from the Four-Center-Exchange $(X-4)$ Format to the Lu'crmore ESCIL Fi' 'itt. December 1978.

- Vol. 2, Rev. 2. A Bbbliography of the Expermental Data of Neutron-Ini ned interactions. July 1976.

- Vol. 3. Rev. 2, An Index of the Experimental Data of Neutron-induced Interactions. July 1976.

- Vol. 4, Rev. 1, Eqaluated Nuclear Dala Library, September 1981.

- Vol. 4, Rev. 1, Appendix C, The Neutron Labrary (ENDL82) in the Trans onttal Format, June 19s2.

- Vol. 5, Part A, Rev. 1, CLYDE: A Code for the Production of Calculational Constants trom .iuclear Data. September 1975.

- Vol. 5. Part B, Rev. 1, Relativistic Transformations between Center-of-Mass and Laborateru Suste'ms tor Two-Body Nuclear Reactions, April 1978.

- Vol. 6. Rev. 2, Tables and Graphs of Photon-Interaction Cross Sections from 1 il to 100 .19el: December 1978.

- Vol. 7, Part A, Rev. 1, Major Neutron-Induced Interactions ( $Z \leq 55)$ : Grap): al, Expermental Data. July 1976.

- Vol. 7. Part 3, Rev. 1, Major Neutron-Induced Interactions ( $Z>55$ ): Grapht. al, Expermental Data, July 1976.

- Vol. 8. Part A, Rev. 1, Supplemental Neutron-Induced Interactions $(Z \leq 35)$ : Graphical, Experimental Data, July 1976.

- Vol. 8, Part B, Rev. 1, Supplemental Neutron-Induced Interactions $(Z>35)$. Graphical, Expirimental Data, July 1976.

- Vol. 9, Threstolds of Nuclear Reactions Induced by Neutrons, Photons, Deuterons. Tritons, and Alphut Particles, September 1970.

- Vol. 10, Rev. 1, Tabulated Experimental Data for Neutron-lnduced Interactions, July 1976.

- Vol. 11, Experimental Dota, Indexes, and Techniques of Obtaining a Selected Set of Neutron Resontmie Parameters, May 1972.

- Vol. 12, An Atlas of Resolved Neufron Resonance Parameters, July 1972.

- Vol. 13, An Aslas of Untesolved Neutron Resonance Parameters, September 1972.

- Vol. 14, TARTNP: A Coupled Neutron-Photon Monte Carlotransport Code, February 1976.

- Vol. 15, Part A, The LLL Evaluated-Nuclear-Data Library (ENDL): Evaluation Techmiques, Reaction Index, and Descriptions of Individual Evaluations, September 1975.

- Vol. 15, Part B, Rev. 1, The LLL Evaluated-Nuclear-Data Library (ENDL): Graphs of Cross Sections from the Library, October 1978.

- Vol. 15, Part C, The LLL Evaluated-Nuclear-Data Library (ENDL): Translation of ENDL NeutronInduced Interaction Data into the ENDF/B Format, April 1976.

- Vol. 15, Part D, Rev. 1, The LLL Evaluated-Nuclear-Data Library (ENDL): Desiriptions of Individual Evaluarions for $Z=0-98$, May 1978.

- Vol. 15, Part E, Data Testing Resuits for the LLL Nuclear Data Library (ENDL-78), August 1979.

- Vol. 15, Part F, Experimental and Evaluated Elastic Nuclear Plus Interference Cross Sections for Light Charged Particles, July 1980.

- Vol. 16, Rev. 2, Tabular and Graphical Presentation of 175 Neutron-Group Constants Derived from the LLL Evaluated-Nuclear-Data Library (ENDL), October 1978.

- Vol. 17, Part A, Rev. 2, Program LINEAR (Version 79-1): Linearize Data in the Evaluated-Nuclear-Data File/Version B (ENDF/B) Format, October 1979. 


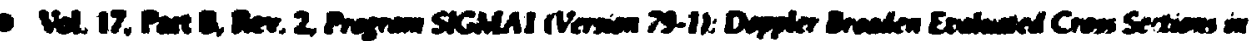

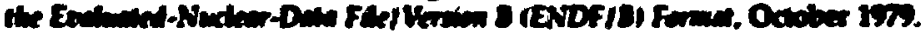

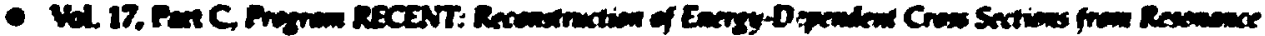

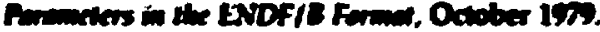

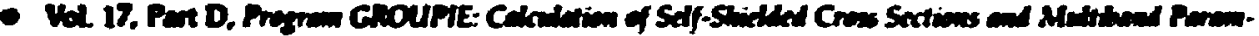

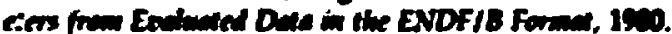

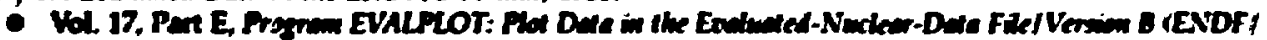
b) Former, February $19 \%$.

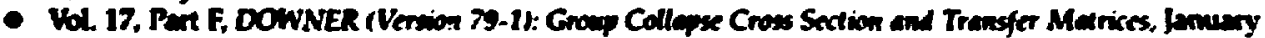
1979.

- Vol. 18, ACTL-Eowluded Nextion Actioution Crose-Section Librars, October 1978.

- Vol. 19, Neutrom-Inimed Angular and Emergy Distributions: Graphical Experimental Data, April 1977.

- Vol. 20. Bonderenko Self-Shielded Cross Sections and Multiband Parameters Derioed from the $u$ Exaluated-Nuclear-Date Librery (ENDL). July 1978.

- Vol. 21, Part A, Maxwell-Averaged Reactions Rates (ow) for Selected Reactions betzreen lons axith Atomic Mass $\leq 11$. February 1979.

- Vol. 21, Part C, Program SIGMAL (Version 79-1): Doppler-Bromdened Enaluated Cross Sections in the Livermore-Evatueted Nuclear Data Lbrary (ENDL) Format, March 1979.

- Vol. 22, Rev. 1, GAMIDEN: A Program to Aid in the Identification of Unknown Materials by GammaRay Spectroscopy. June 1982.

- Vol. 23. ENSL and CDRL: Evaluated Nuclear Structure Libraries, February 1981.

- Vol. 23, Addendum, ENSL82 and CDRL82: The 1982 Version of Eoaluated Nuclear Structure Libraries, January 1983.

- Vol. 24, Thresholds and Q Values of Nuclear Reactions Induced by Neutrons, Protons, Deuterons, Tritons, He Ions, Alpha Particles, and Photons, March 1981. 


\section{ENSLer and CDRLer. \\ The 1992 Version of Evaluated \\ Neclear Structure Libraries \\ ENSL and CDKL}

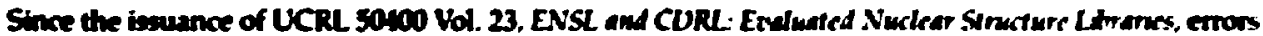
hrve been nowed in half-lives. Most of these errors were for half-lives represented in exponential form, where the exponent is positive. This situation occurs only when the unit for half-life is "years." A few erros mere aesociated with ground states having unknown half-lives. These were incorrectly labeled as stable (ie., a value of $1.0 \mathrm{E}+50 \mathrm{~s}$ was entered). Such ground states are assigned half-lives of $1.0 \mathrm{E}-20 \mathrm{~s}$ in the new version of the two data files. In all, we found a total of 65 levels that had incomect half-lives. These levels and the corrected half-lives are listed in Table 1.

Those who have microfiche listings of the data files may wish to consult Table I as a check before using the microfiche.

Those who wish to have computer-readable files may obtain ENSL82 and CDRL82 on magnetic tape. on request. On magnetic tape, ENSL82 and CDRL82 are available as one blocked file each or as four and five biocked files, respectively. In the latter case, each blocked file corresponds to the $Z$ ranges in Table 2 . which shows the appropriate statistical data for each file. Request for magnetic tape of the data may be directed to the National Nuclear Data Center, Brookhaven National Laboratory, Upton, New Yous; to the Radiation Shielding Information Center, Oak Ridge National Laboratory, Oak Ridge. Tennessee; or to the Nuclear Data Section, International Atomic Energy Agency, Vienna, Austria.

It is certainly possible, and even likeiy, that there are still errors in these files. 1 shall be grateful to any user who informs me of such errors so they may be corrected for the next version. I am pleased to thank Dr. Fred Mann, of the Hanford Engineering Development Laboratory (HEDL), who told me of one such error in the previous version. 


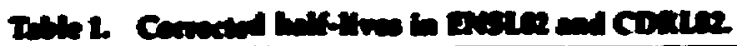

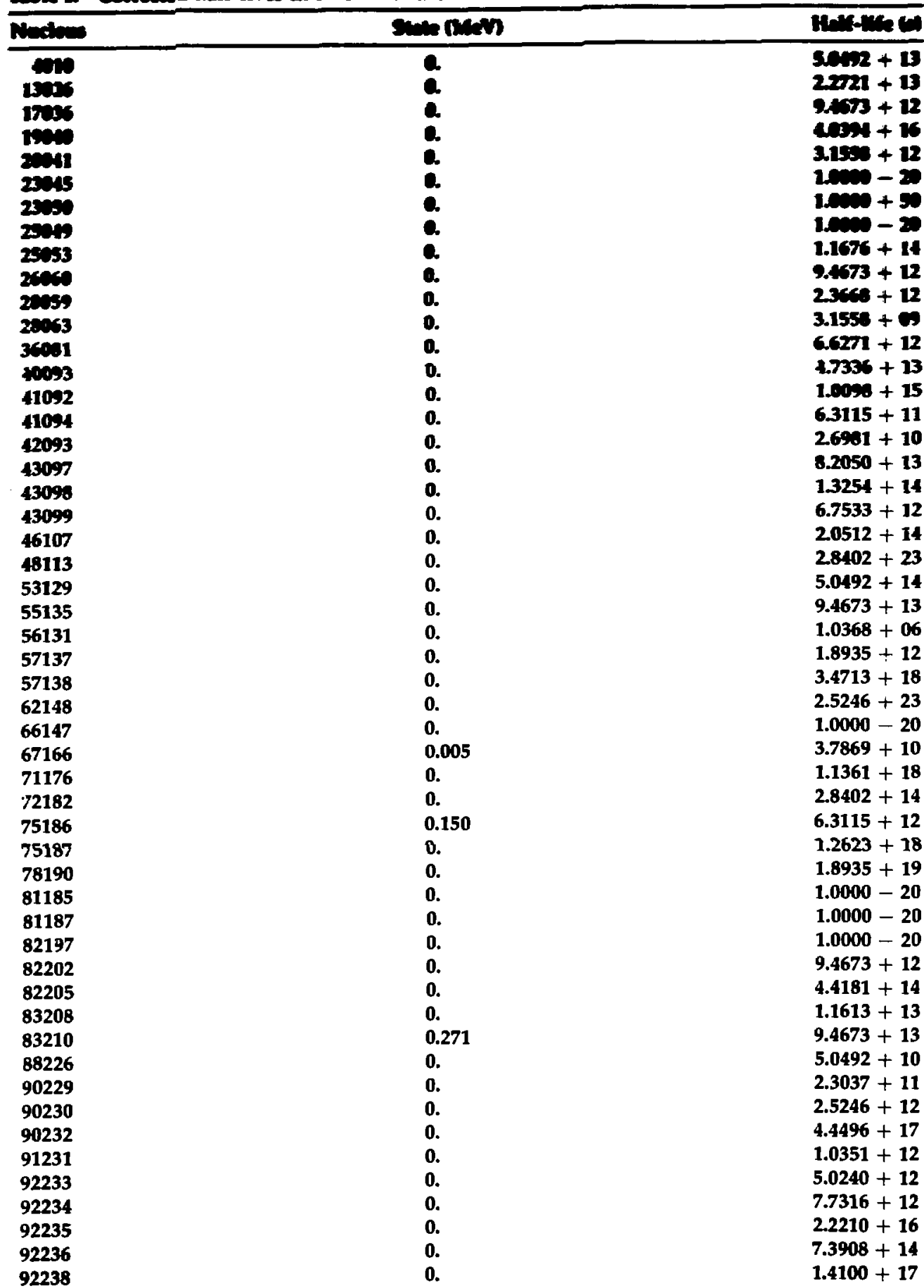


Tolle 1. Conainand

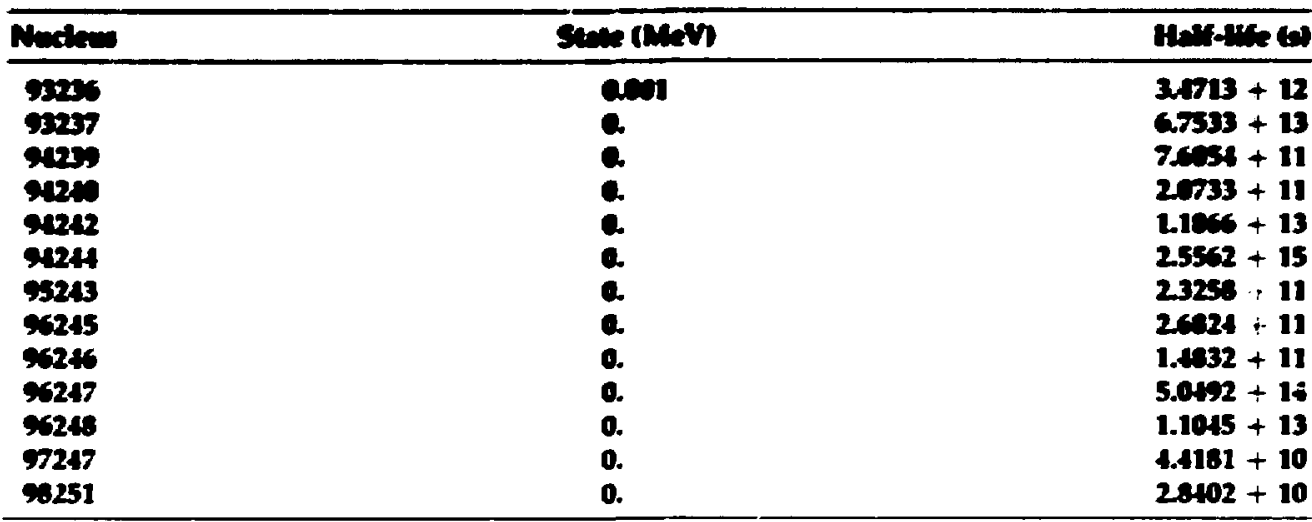

Table 2 Statistical data for each evaluated nuclear structure file.

\begin{tabular}{|c|c|c|c|}
\hline Number of & & $\begin{array}{c}\text { CDRL82 } \\
1553\end{array}$ & $\begin{array}{c}\text { ENSL82 } \\
1481\end{array}$ \\
\hline Number of & & 41209 & 15378 \\
\hline Maximum r & & 72 & 72 \\
\hline Maximum & pe & 142 & 86 \\
\hline File & Z-Range & & Number of records \\
\hline CDRL82-1 & $1-19$ & & 11521 \\
\hline CDRL82-2 & $20-39$ & & 25526 \\
\hline CDRL82-3 & $40-59$ & & 32039 \\
\hline CDRL82-4 & $60-79$ & & 38615 \\
\hline CDRL82-5 & $80-105$ & & 18216 \\
\hline ENSL82-1 & $1-24$ & & 2767 \\
\hline ENSL82-2 & $25-49$ & & 17746 \\
\hline ENSL82-3 & $50-74$ & & 27429 \\
\hline ENSL82-4 & $75-105$ & & 15443 \\
\hline CDRL82 & $1-105$ & & 125913 \\
\hline ENSL82 & $1-105$ & & 63382 \\
\hline
\end{tabular}

